\title{
ECOLOGICAL STUDIES ON THE BUTTERFLY MANIOLA JURTINA IN BRITAIN. I. ADULT BEHAVIOUR, MICRODISTRIBUTION AND DISPERSAL
}

\author{
BY PAUL M. BRAKEFIELD
}

Department of Genetics, University of Liverpool, Brownlow Street, Liverpool L69 3BX

\section{SUMMARY}

(1) The behaviour, microdistribution and dispersal of the meadow brown butterfly Maniola jurtina was investigated using mark-release-recapture techniques.

(2) The main study site was a meadow at Hightown near Liverpool where a grid of $7 \cdot 5 \mathrm{~m}$ squares was established.

(3) Butterflies showed an aggregated microdistribution at Hightown. Intraseasonal changes and differences between years (generations) in microdistribution were correlated with changes in the distribution of clumps of flowering plants. Such changes in males were probably also influenced by the distribution of emerging females. The sexes showed statistically different microdistributions associated with differences in resource requirements.

(4) A low rate of movement from areas of favourable habitat was detected (38 out of 1568 recaptures). The frequency distribution of the distance moved by $M$. jurtina at Hightown was leptokurtic. Butterflies tended to restrict their activity to familiar areas within the habitat of this population. The home range $(95 \%)$ of individuals was estimated as $0.85 \pm 0.065$ ha. Inspection of the data indicated that this is anderestimate. Preliminary evidence for individual variation in dispersal behaviour is examined.

(5) Males and females showed similar dispersal rates. However, males fly more often than females. Males show a characteristic exploratory flight for mates. Females fly to lay eggs and to feed. Nectar is probably a more important resource for females than males.

(6) The present study confirms the hypothesis of Handford (1973) that male and female M. jurtina occupy different ecological niches.

\section{INTRODUCTION}

The meadow brown butterfly Maniola jurtina (L.) exhibits considerable variation in the spot pattern of its hindwings. For this reason it has been extensively studied by ecological geneticists (see reviews by Ford 1975; Brakefield 1982a). Their work has not been conducted with an extensive ecological understanding of this species, though some authors have suggested that examples of differences in spot variation between populations and of changes between generations were due to selective forces associated with differences in habitat (McWhirter 1957; Dowdeswell \& Ford 1955; Dowdeswell, Ford \& McWhirter 1957, 1960). It has also been suggested, in relation to the marked differences in spot variation between the sexes of $M$. jurtina, that these occupy different ecological niches and are subject to differing selection (Handford 1973; see also Scali \& Masetti 1975). Before

Present address: Department of Biological Sciences, University of Exeter, Perry Road, Exeter EX4 4QG. 
such hypotheses can be tested it is necessary to examine the basic population ecology of the species. This paper therefore describes observations on the behaviour and movement of adult males and females. They were made in conjunction with a study of population dynamics (Brakefield 1982b). I shall use the term dispersal to describe the normal movement (as a result of its daily activty) of an insect under its own power in its lifetime. Microdistribution refers to the distribution in space within the population boundary.

\section{METHODS}

M. jurtina is a univoltine butterfly which is abundant in a wide variety of grassland habitats in the British Isles. The species was studied at West Kirby west of Liverpool and at Hall Road and Hightown on the coast north of Liverpool. The smallest site at West Kirby $(0.67$ ha) was a rough area of grass growing over an old garden. The largest site at Hall Road ( 3 ha) was a meadow supporting a rich flora. Damp conditions predominated here and parts were almost a marsh habitat. The most extensively studied population was at Hightown in an old meadow (of 1.36 ha) which had not been disturbed for at least 20 years. Details of the habitat subunits which could be distinguished are given in Fig. 1. The meadow had a diverse flora and insect fauna. Insectivorous birds, mammals and lizards were also present. The habitat surrounding each site was generally unsuitable for M. jurtina.

Multiple mark-release-recapture experiments were performed at each site (see Table 1 of Brakefield 1982b). Butterflies were marked uniquely at first capture. Marks were inconspicuous dots on the ventral surface of the wings. Laboratory observations showed that they could be distinguished throughout a butterfly's life span. On initial capture the following data were recorded: (i) time and date of capture; (ii) sex and spot pattern; (iii) position of capture (except at West Kirby); (iv) behavioural activities of the butterfly

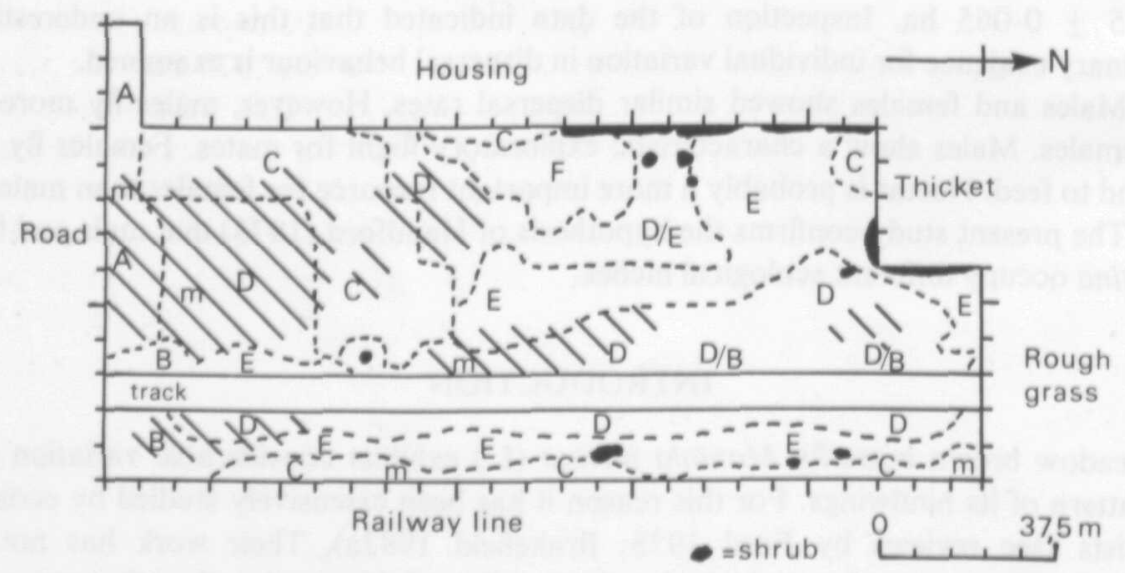

FIG. 1. The search area at Hightown. Grid units are indicated on the outside of the perimeter line. Details are shown of the habitat subunits (capital letters) and of the areas where larvae of Maniola jurtina were collected (hatched) and pairs in copula were captured (marked m). A, low bank with fairly high herbage $(>40 \mathrm{~cm})$. Quite well-drained with fine leaved grasses and rich in nectar sources including Cirsium spp.; B, short grass $(<20 \mathrm{~cm})$ with patches of nectar sources, particularly Trifolium and Rubus spp.; C, hillocks covered with long grass $(>50 \mathrm{~cm})$. Fine leaved grasses and flowers in hollows; D, flat areas of fine leaved grass species (incl. Lolium and Poa) with flowering clumps of Cirsium and Centaurea spp.; E, flat areas, less well-drained with high herbage $(>50 \mathrm{~cm})$ of predominantly coarse leaved grasses. Some clumps of Cirsium spp.;

$\mathrm{F}$, dry area of poor short grass $(<15 \mathrm{~cm})$ or bare sandy soil. 
immediately prior to its disturbance and capture; (v) physical condition of the wings, this being described by a system similar to that employed by Watt et al. (1977) for Colias butterflies. On recapture, the time, date, capture position, behavioural activity and reference number were recorded. All butterflies were released at their point of capture. The procedure of capture, handling (including marking) and release was undertaken as quickly as possible whilst at the same time attempting to minimize its effect. As far as possible a population was sampled on each day of an experiment. During sampling the area was searched systematically and in a manner that was consistent from one occasion to another.

At Hall Road in 1978 a grid of 20 m squares was established in approximately a $9 \times 9$ arrangement. The population at Hightown in 1976 was sampled with reference to a series of fifteen capture-release sites. Most animals were captured at or near these sites. In the following 2 years a grid of $7.5 \mathrm{~m}$ squares was established (Fig. 1).

The capture co-ordinates at Hightown in 1977 and 1978 were used to map the microdistribution of adults. Records for same-day recaptures ( $\approx 10 \%$ of total), providing at least $30 \mathrm{~min}$ had elapsed since initial capture, are combined with those for daily recaptures. The microdistribution for two defined subpopulations can be compared by the $\log$-likelihood ratio $(G)$ test (Sokal \& Rohlf 1981). The observed frequency of the capture events for each group in each grid square is treated as a separate trial with the expected ratio of frequencies equal to the proportion of each group in the total captures. Squares in which no or one capture was recorded are excluded from the calculation. A significant value of $G$ indicates that the two distributions are different. In order to reduce the influence on this test of squares with small numbers of captures, the 1977 data are also analysed by combining the $7.5 \mathrm{~m}$ squares in groups of four to give $15 \mathrm{~m}$ squares. The randomness of each microdistribution is tested by Chi-square comparison of the observed and expected frequency of captures per grid square. The expected is calculated using the Poisson function.

Adult dispersal was studied by analysis of the straight line distances between consecutive capture points made on separate daily sampling occasions. The capture co-ordinates for individual butterflies at Hightown were analysed further. For the 1976 data the maximum range is calculated for butterflies captured three or more times. This is the longest distance between two capture points. More precise estimates for the area of activity of butterflies can be calculated from the data collected using a grid. A minimum area estimate is obtained by mapping the capture points (when $\geqslant 4$ ) and measuring the area enclosed by the outermost points when these are joined up (Southwood 1966). A second estimate is obtained by calculating the elliptical home range using the method described by Mazurkiewicz (1969) and outlined by Randolph (1977). Values for home range are those estimated to enclose $95 \%$ of a butterfly's activity.

Some additional observations on adult behaviour and movement were made at a number of sites in central-eastern Scotland (see Table 5 of Brakefield 1982b).

\section{RESULTS}

\section{Description of adult behaviour}

Table 1 shows that males spend more time flying than females. The behaviour of males when seeking mates is intermediate between that characteristic of patrolling species and of perching species of butterflies (sensu Scott 1974). Males tend to alternate between periods of flight and rather longer intervals of resting, usually on vegetation, during which any 
TABLE 1. The frequency of some behavioural activities of Maniola jurtina recorded immediately prior to capture in 1977 (observations were made when conditions were suitable, but not necessarily optimal, for activity)

\begin{tabular}{|c|c|c|c|c|c|}
\hline Sex & Flying & $\begin{array}{l}\text { Activity } \\
\text { Resting }\end{array}$ & Feeding & Total & $\begin{array}{c}\text { Percentag } \\
\text { flying }\end{array}$ \\
\hline \multicolumn{6}{|c|}{ Hightown population } \\
\hline males & 239 & 132 & 27 & 398 & $60 \cdot 1$ \\
\hline females & 33 & 44 & 9 & 86 & 38.4 \\
\hline \multicolumn{6}{|c|}{ Scottish populations $(n=16)$} \\
\hline males & 245 & 47 & 25 & 317 & $77 \cdot 3$ \\
\hline females & 255 & 204 & 87 & 546 & 46.7 \\
\hline
\end{tabular}

butterfly which flies within sensory range may be investigated. Whilst searching for females, males show a characteristic slow exploratory flight which is close to the vegetation and has relatively frequent and sharp changes in direction. Courtship is short with few preliminaries. It is similar to that of Hipparchia semele (Tinbergen et al. 1942). In contrast to males, females fly primarily to deposit eggs and to feed. In the laboratory females usually lay several eggs within a short time followed by a period of no oviposition.

There is evidence, particularly for populations in Scotland $\left(\chi_{1}^{2}=11.50, P<0.001\right)$, that females feed on nectar more frequently than males (Table 1). Some females at Hightown were observed to feed on flowers for periods of up to $58 \mathrm{~min}$. Males feed for shorter periods and are more active whilst feeding, sometimes investigating passing butterflies. The most popular source of nectar was thistle (Cirsium spp.), $72 \cdot 3 \%(n=107)$ of all butterflies seen feeding in 1977 were on these plants. Noteworthy among the many other nectar sources visited by $M$. jurtina were species of Centaurea, usually $C$. nigra. Feeding butterflies and pairs in copula were encountered throughout the daily period of adult activity.

M. jurtina sometimes regulates its temperature by dorsal basking behaviour (opening and closing their wings perpendicular to sunlight, Clench 1966). Of those butterflies which were not initially observed in flight in $1977,5 \cdot 7 \%(n=33)$ had their wings in an open position. Butterflies usually roost head uppermost whilst resting on ground vegetation.

\section{Microdistribution}

In the spring of 1976 and 1977 larvae which had passed through the winter period of slow growth were collected at Hightown by sweeping the vegetation with a strong net at night. Although the efficiency of sweeping is low and varies in relation to vegetation cover, the sampling indicated that larvae tended to be restricted to areas where the vegetation was of an intermediate height and consisted of herbs and predominantly fine-leaved grasses (see Fig. 1). The few females which were observed ovipositing at Hightown were found in such areas. In grass enclosures fine leaved grasses, including species of Poa and Lolium, are preferred as food plants by larvae (Brakefield 1979). Coarse and hirsute leaved grasses are not selected. These predominated in areas of high vegetation at Hightown.

The $M$. jurtina captured in copula at Hightown were located in areas with vegetation of intermediate height (Fig. 1). The mate-location behaviour of males is concentrated in such areas. The probability that a male has of mating will depend on the density of receptive females and on the efficiency with which it can locate, approach and copulate with one of these. Both these factors will vary in relation to the vegetation structure. 
The microdistributions for adults of each sex are shown in Fig. 2. Although fewer females were captured, there is statistical evidence that in each year the sexes show a different microdistribution (Table 2). A corresponding difference is found in 1976 for the proportion of males and females captured at each capture-release site $(G=28.40$, d.f. 11 , $P<0.01)$. In that year the sample size and the estimated density of each sex was similar (Brakefield 1982b).

Males show an aggregated microdistribution (Table 2). In both 1977 and 1978 there is a heavy concentration of captures along a low bank at the southern end of the grid (Figs 1 and 2). Such slightly elevated areas may be preferred resting sites for males because they can detect females at greater distances. In both sexes many captures were made near the centre of the grid where low hillocks supported a vegetation relatively rich in nectar sources and larval food plants. In 1977 (Table 2$)$ and for both years combined $\left(s^{2} / \bar{x}=2 \cdot 50, \chi_{1}^{2}=\right.$ 16.58) the observations of feeding adults show an aggregated distribution. A concentration of captures occurred in 1977 towards the north-west of the grid where large clumps of Cirsium amongst high vegetation were visited for nectar throughout the flight period. In 1978 these clumps did not begin to flower until the fourth week of the flight period. This contrast is reflected in the microdistributions (Fig. 2) which were significantly different between years (males: $G=211.08$, d.f. 141 ; females: $G=87.07$, d.f. $48, P<0.001$ for both values). An influence on microdistribution of the degree of synchronization between the flight period of $M$. jurtina and the flowering of principal nectar sources was also apparent in 1976. The flight period was relatively advanced in the hot and dry summer of that year. There was a close concurrence between it and the flowering of large clumps of Centaurea nigra at Hightown (in the following years they did not begin to flower until the mid-late flight period). The proportion of captures made at these clumps in three central capture-release sites together with a clump of Cirsium arvense in the north-west corner was $36 \cdot 1 \%(n=179)$ of males and $47.6 \%(n=250)$ of females. The difference between the sexes is highly significant $\left(\chi_{1}^{2}=13.92\right)$ and is consistent with the hypothesis that females spend more time feeding than males.

In addition to changes in microdistribution between years there were also changes within flight seasons (Table 2). Males tended to be captured further towards the northern end and

TABLE 2. Variance-to-mean ratios for microdistributions of adult Maniola jurtina at Hightown; values greater then unity indicate contagion. Microdistributions are compared by means of the log-likelihood ratio $(G)$ test (d.f. are given in brackets)

\begin{tabular}{|c|c|c|c|c|c|c|c|c|}
\hline \multirow[b]{3}{*}{ Sample } & \multirow{2}{*}{\multicolumn{2}{|c|}{$\begin{array}{l}\text { Number of } \\
\text { captures }\end{array}$}} & \multirow{2}{*}{\multicolumn{4}{|c|}{1977}} & \multirow{2}{*}{\multicolumn{2}{|c|}{$\begin{array}{c}1978 \\
\text { by } 7.5 \mathrm{~m} \text { sqs }\end{array}$}} \\
\hline & & & & by $7.5 \mathrm{~m}$ sqs & by $15 \mathrm{~m}$ sqs & & & \\
\hline & 1977 & 1978 & $s^{2} / \bar{x}$ & G & $s^{2} / \bar{x}$ & G & $s^{2} / \bar{x}$ & $G$ \\
\hline $\begin{array}{l}\text { Sex } \\
\text { females }\end{array}$ & 83 & 105 & $1.78^{*}$ & $\begin{array}{c}159 \cdot 2^{* * * *} \\
(104)\end{array}$ & $2 \cdot 06^{*}$ & $\begin{array}{r}74 \cdot 6^{*} \\
(51)\end{array}$ & & $\begin{array}{l}130 \cdot 9 * * * \\
(101)\end{array}$ \\
\hline males & 389 & 306 & $2.57^{* * * *}$ & & $5 \cdot 09^{* * *}$ & & $2 \cdot 56^{* * *}$ & \\
\hline $\begin{array}{l}\text { Date of capture, } n \\
\text { early } \dagger\end{array}$ & $\begin{array}{c}\text { males } \\
187\end{array}$ & 129 & $2 \cdot 01^{* * * *}$ & $\begin{array}{l}145 \cdot 1^{* * * *} \\
(89)\end{array}$ & $4 \cdot 31^{* * *}$ & $\begin{array}{l}78 \cdot 9^{* *} \\
(48)\end{array}$ & $2 \cdot 15^{* * *}$ & $\begin{array}{c}127 \cdot 5^{* * *} \\
(74)\end{array}$ \\
\hline late† & 202 & 177 & $1.48^{* * * *}$ & & $3 \cdot 20^{* * * *}$ & & $1 \cdot 64^{* * *}$ & \\
\hline $\begin{array}{l}\text { Feeding positions } \\
\text { all }\end{array}$ & 36 & 31 & $\begin{array}{l}1.68 * * * \\
* P<0.05\end{array}$ & ${ }^{*} P<0.01$ & $\begin{array}{l}1.87 * * \\
* P<0.001\end{array}$ & & 1.76 & \\
\hline
\end{tabular}




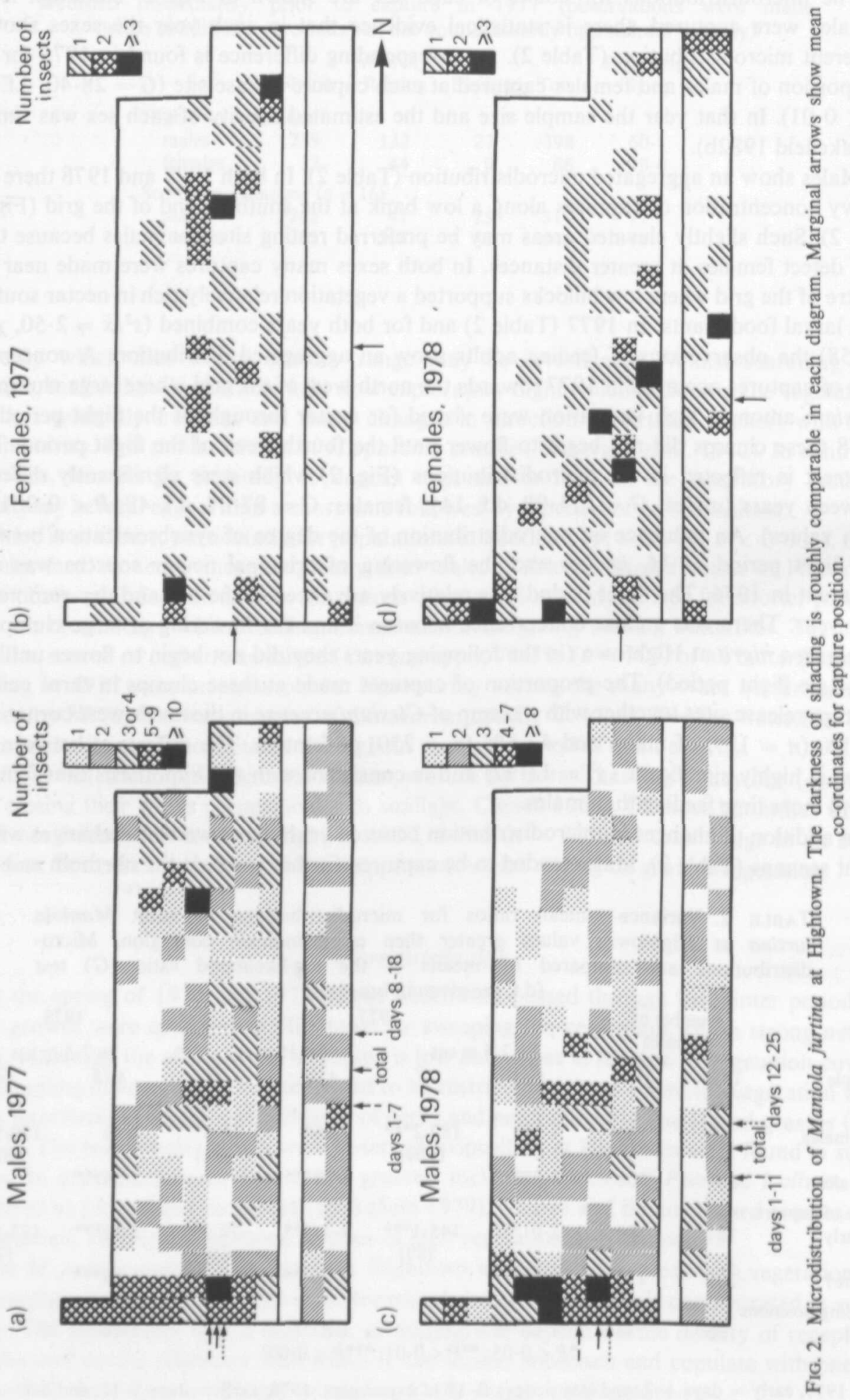


the eastern perimeter of the grid in the latter part of each experiment (mean positions are indicated in Fig. 2). Table 2 also suggests that they became less aggregated. A similar change in the distribution of captures occurred in 1976. These changes may be caused by the changes in availability of females. Larvae are commoner in the southern part of the grid (Fig. 1). As the number of females emerging in this area declines, the probability of a male encountering a receptive female will also decrease. The time that a male remains within a particular area will presumably be proportional to its expectation of obtaining a mate. A similar effect could result in the southern areas of the grid through an increased rate of encounters between males as their density increases during the period of emergence. Interactions sometimes occur when two males meet. These may lead to a short displacement of one or both participants.

\section{Within-habitat movement}

Table 3 shows that the capture of a butterfly does not result in any obvious change in its subsequent dispersal behaviour.

The most suitable data, those for males at Hightown in 1977 , were analysed to test for randomness in the direction of movement. The analysis was carried out for those movements which began at least three grid squares from the perimeter of the grid and ended within a square whose edge did not extend beyond the perimeter. There is no evidence for a non-random (unequal) distribution in the direction of movement (analysis with four sectors: $\chi^{2}=0.25$ and 1.08 for numbers of, and total distance of, movements respectively, $P>0 \cdot 1)$.

\section{Rate of dispersal}

The distribution of the distances of movements detected at Hightown will be influenced by many factors in addition to the natural dispersal behaviour and microdistribution of $M$. jurtina. The most important of these are the shape and size of the search area $(187.5 \mathrm{~m}$ by $75 \mathrm{~m}$ ) and, in 1976, the matrix of distances between capture-release sites (longest $=138$ m). For males at Hightown (in 1977) and also at Hall Road the mean distance from the perimeter of the search area to the mean capture position $(60.5 \mathrm{~m}$ and $95 \mathrm{~m}$ respectively) is at least $16 \%$ longer than the mean distance moved by day 1 or total recaptures in each experiment (Fig 3 and Table 4). Fig. 3(a) includes a comparison of the observed increase in distance moved with time for females at Hightown in 1976 with that expected from a random diffusion model where the constant step length is defined as the distance traversed

TABLE 3. The effect of intervening captures on the distance moved in metres by (mean $\pm 95 \%$ C.L.) over different periods of days by Maniola jurtina at Hightown ${ }^{\dagger}$

Number of

intervening captures

Females (1976)

0

1

2-4

Males (1977)

0
1
$2-8$

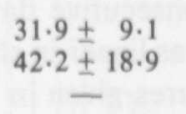

$45 \cdot 5 \pm 12 \cdot 0$ $48.9 \pm 9.1$
Duration of movements in days

3

$48.1 \pm 12.1$
$51.6 \pm 21.8$
$50.0 \pm 38.1$
$40.7 \pm 9.9$
$51.5 \pm 12.5$
$50.6 \pm 15.6$

$$
\begin{aligned}
& 50 \cdot 2 \pm 16 \cdot 9 \\
& 36 \cdot 6 \pm 13 \cdot 7 \\
& 21 \cdot 3 \pm 24 \cdot 9 \\
& 54 \cdot 5 \pm 21 \cdot 4 \\
& 53.2 \pm 13 \cdot 1 \\
& 54.9 \pm 14 \cdot 5
\end{aligned}
$$

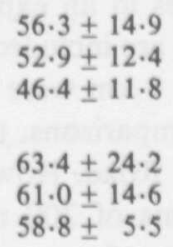

+ The C.L. statistics are not reliable because the required assumption that the sample data are normally distributed is not always valid (see text). 


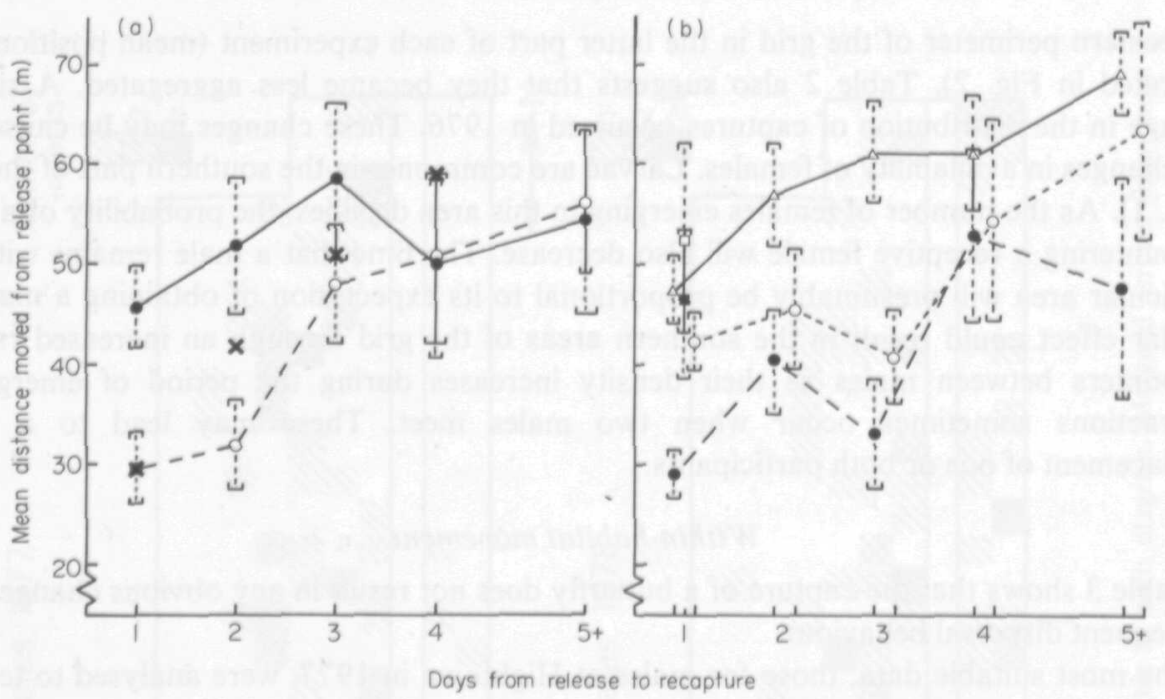

FIG. 3. Mean distance moved by Maniola jurtina with time from release. Vertical bars show standard errors. Movements of 5 days or longer are combined. (a) Hightown 1976:

males; -- - , females. $\mathbf{X}$, predicted dispersal from random step model for females (see text). (b) Hightown 1977: … O, males ( $\square$, females); 1978: - - males ( $\mathbf{\square}$, females). Hall Road 1978: $\longrightarrow$, males.

TABLE 4. The distance moved $(\mathrm{m})$ by male and female Maniola jurtina at the localities indicated

Females

\begin{tabular}{|c|c|c|c|c|c|c|c|}
\hline Population & Year & $n$ & $\begin{array}{c}\text { Mean } \\
\text { distance } \\
\text { moved } \\
( \pm \text { S.E. })^{*}\end{array}$ & $\begin{array}{l}\text { Mean } \\
\text { duration } \\
\text { of a move } \\
\text { (days) }\end{array}$ & $n$ & $\begin{array}{c}\text { Mean } \\
\text { distance } \\
\text { moved } \\
( \pm \text { S.E. })^{*}\end{array}$ & $\begin{array}{c}\text { Mean } \\
\text { duration } \\
\text { of a move } \\
\text { (days) }\end{array}$ \\
\hline $\begin{array}{l}\text { Hightown } \\
\text { Hightown }\end{array}$ & 1976 & 227 & $40.2 \pm 2.5$ & $2 \cdot 6$ & 147 & $50.7 \pm 2.9$ & $\begin{array}{l}2.5 \\
1.8\end{array}$ \\
\hline Hightown & 1977 & 40 & $48.4 \pm 6.7$ & 1.9 & 234 & $45.2 \pm 2.2$ & 1.8 \\
\hline Hightown & 1978 & 61 & $43.7 \pm 4.4$ & $2 \cdot 3$ & 199 & $34.9 \pm 2.1$ & $2 \cdot 0$ \\
\hline Hall Road & 1978 & & & & 348 & $59.0 \pm 2.1$ & 3.9 \\
\hline St Andrews & 1977 & $\begin{array}{l}33 \\
31\end{array}$ & $\begin{array}{l}68.3 \pm 10.9 \\
58.2+8.2+\end{array}$ & 1.4 & $\begin{array}{l}32 \\
29\end{array}$ & $\begin{array}{l}66.7 \pm 12.4 \\
49.1 \pm 8.3+\end{array}$ & 1.6 \\
\hline
\end{tabular}

* The statistics are not reliable because the required assumption (that the sample data are normally or continuously distributed) is not always valid.

+ Excludes movements of $200 \mathrm{~m}$ or longer.

between release and day 1 . For these data this distance is relatively small which will reduce bias due to the size of the search area. Even so, the comparison indicates some restriction of movement over the first 4 days following release. Details of the distance moved by recaptures in an experiment performed on four consecutive days near St Andrews in E. Scotland are included in Table 4. The search area was linear in shape and movements of up to about $1 \mathrm{~km}$ were possible. Inspection of the figures given in Table 4 suggests that, for some comparisons, the mean distance moved at St Andrews is longer than at Hightown and Hall Road. However, the differences are considerably reduced if the small number of movements of $200 \mathrm{~m}$ or longer are excluded from the St Andrews data (Table 4). The proportion of movements of less than $30 \mathrm{~m}$ at St Andrews was similar to that at Hightown in the same year $(41.8 \%$ and $43.4 \%$ respectively). These observations suggest that the size 
of the search area at Hightown is not small in relation to the dispersal behaviour of $M$. jurtina.

There is no obvious difference in dispersal rates of the sexes (Table 4). Fig. 4 shows the frequency of dispersal distances at Hightown for the mot extensive sets of data for each sex. The observed distributions for both day 1 and total recaptures are compared with the corresponding normal distributions having the same variance. When the effects of the dimensions of the search area and of scaling are considered the comparisons suggest that $M$. jurtina shows a leptokurtic distribution of dispersal distances. This is particularly evident in the observed excess of long movements. These are likely to be underestimated because of the nature of the data.

The interaction between dispersal and microdistribution is illustrated by the difference in dispersal rate of males at Hightown between 1977 and 1978 (Mann-Whitney test, $Z=$ 3.33, d.f. 234 and 199, $P<0.001$ ). In 1978 there was a higher proportion of short movements and fewer long movements between the ends of the grid. This was associated with a lower proportion of captures towards the northern end of the grid (Fig. 4 and see above).

\section{Area of activity}

Fig. 5 shows that the estimates for the minimum area of activity for individual males at Hightown tend to increase with increasing number of capture points. There is no clear
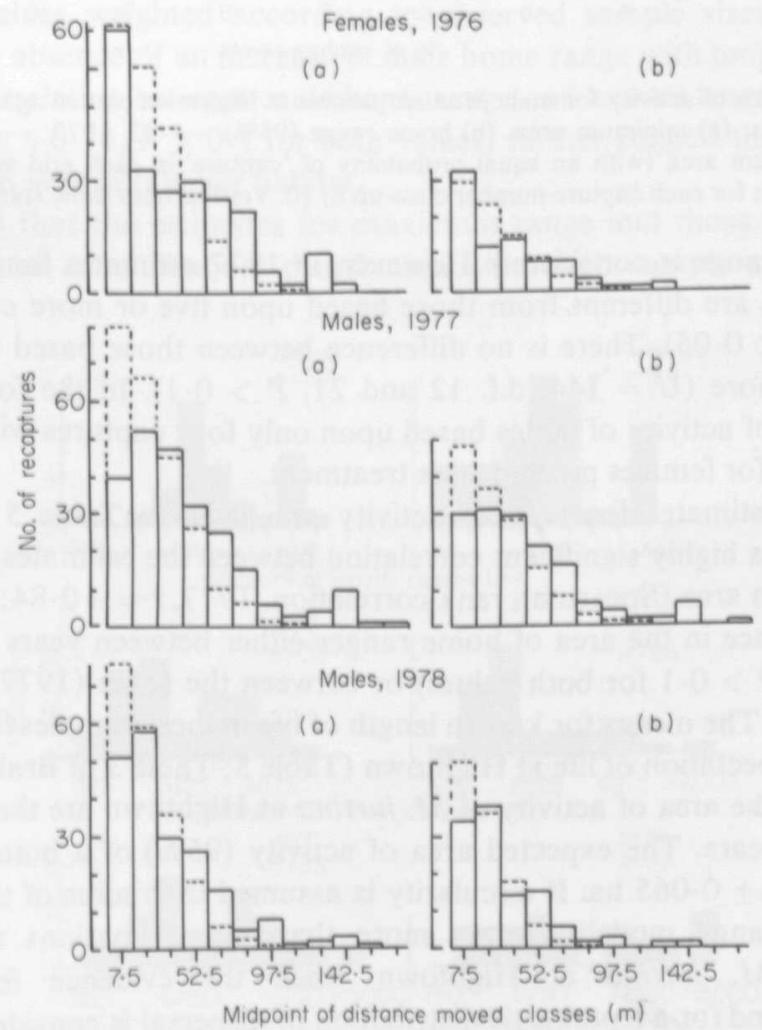

FIG. 4. Frequency of dispersal distances of Maniola jurtina at Hightown. (a) total recaptures, (b) day 1 recaptures. Broken lines show normal distributions having the same variance. 

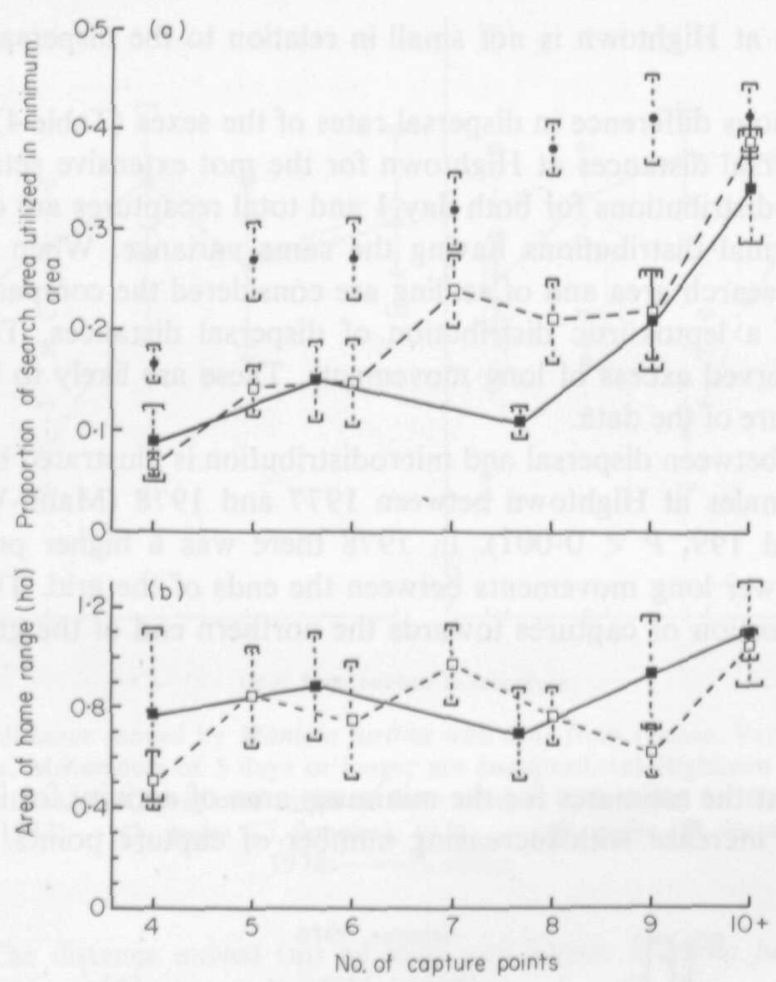

FIG. 5. Mean area of activity for male Maniola jurtina at Hightown plotted against the number of capture points. (a) minimum area, (b) home range $(95 \%)$. $---\square, 1977$; $-\mathbf{E}, 1978$, expected minimum area (with an equal probability of 'capture' in each grid square) obtained from ten trials for each capture-number class up to 10 . Vertical bars show standard errors.

trend when home range is considered. However, in 1977 estimates for home range based upon four captures are different from those based upon five or more captures $(U=304$, d.f. 13 and $33, P<0.05$ ). There is no difference between those based upon five captures and upon six or more $(U=144$, d.f. 12 and $21, P>0.1)$. In the following discussion estimates for area of activity of males based upon only four captures will not be examined. Small sample sizes for females preclude this treatment.

Details of the estimates for area of activity are given in Table 5 (sample sizes are included). There is a highly significant correlation between the estimates for males of home range and minimum area (Spearman rank correlation, 1977, $r=+0.84 ; 1978, r=+0.88$ ). There is no difference in the area of home ranges either between years (males, $Z=0.46$; females, $U=64, P>0.1$ for both values) or between the sexes $(1977, Z=1.02 ; 1978$, $U=202, P>0.1)$. The means for known length of life in these samples fall within the range of estimates for expectation of life at Hightown (Table 5; Table 3 of Brakefield 1982b). The best estimates for the area of activity of $M$. jurtina at Hightown are those for home range of males in both years. The expected area of activity (95\%) of a butterfly during its life span is then $0.849 \pm 0.065$ ha. If circularity is assumed the radius of this area is $52.0 \mathrm{~m}$. However, home range models are no more than approximations to reality. This is emphasized for $M$. jurtina at Hightown when the evidence for a non-random microdistribution and for a leptokurtic distribution of dispersal is considered since a normal distribution of capture points along each axis of the ellipse is implicit in the calculation of home range. Furthermore, many of the home range ellipses extended beyond the periphery 
TABLE 5. Estimates for the area of activity $\left(\mathrm{m}^{2}\right)$ of Maniola jurtina at Hightown.

The S.E. of each mean area and some details of capture histories are given

Males

$$
1977
$$

Sample size

Mean number of captures

Mean known length of

life (days)

Area of activity:

minimum area home range (95\%)*
33

7.03

7.67

$2601+2552579+316$

$8136+8348947+1052$

Females

1977

9

$5 \cdot 11$

5.44

$2162+4201283+205$

$9925 \pm 2256 \quad 6010 \pm 956$

* Values for home range estimated to enclose $63.2 \%$ of a butterfly's activity are only slightly larger, on average, than those for minimum area. For statistical comparisons (see text) of the sexes, $n$ males $=46$ (1977) and 34 (1978).

of the grid. In an open population inhabiting a continuous habitat of a similar type to that at Hightown the expected area of activity is likely to be rather larger than that estimated at Hightown.

The restricted movement of $\boldsymbol{M}$. jurtina at Hightown is apparent when estimates for minimum area of males in each capture-number class are compared with expected values if intercapture movement were random throughout the grid (Fig. 5(a)). Overall, the observed mean minimum area is $60.1 \%(1977)$ and $54.2 \%(1978)$ of that calculated from the expected mean values weighted according to observed sample sizes for each capturenumber class. The absence of an increase in male home range with more than five captures and the lack of correlation between male home range and known length of life $\left(1977, r_{s}=\right.$ $+0.24 ; 1978, r_{s}=+0.14, P>0.1$ for both values) further suggest that butterflies tended to remain within an area of familiar habitat.

Fig. 6 indicates that the estimates for maximum range and those for area of activity show some evidence of a bimodal distribution. Although sample sizes are small, this

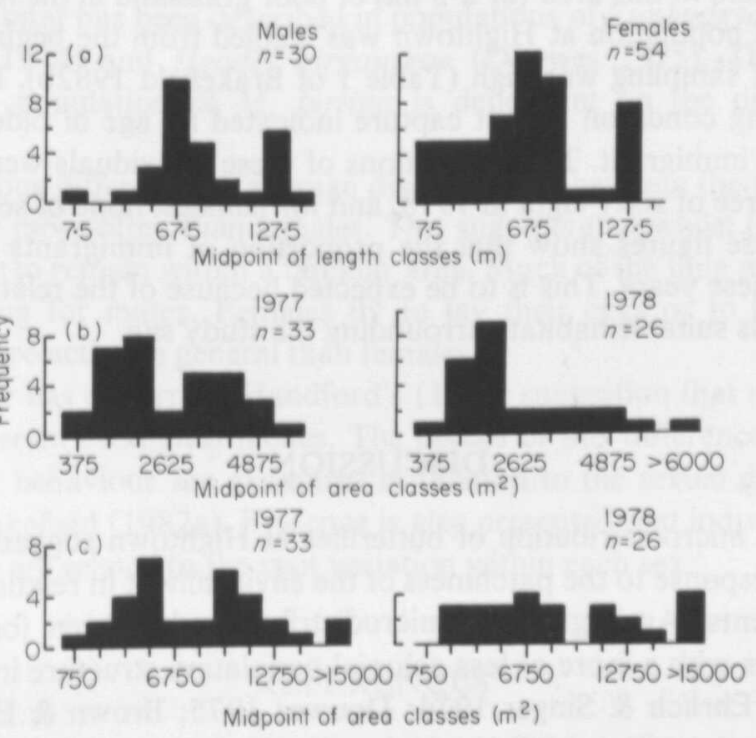

FIG. 6. Histograms for estimates of dispersal of individual Maniola jurtina at Hightown. (a) maximum range, 1976; (b) minimum area, males; (c) home range, males. 
suggests that some $\boldsymbol{M}$. jurtina at Hightown tend to be sedentary in comparison to others which move through most of the search area in their life span.

\section{Between-habitat movement}

In the capture-recapture experiments in England and Scotland movement was detected from or between sites of relatively high density separated by unsuitable habitat where $M$. jurtina was at low density. Eighteen males and twenty females made displacements of this type. The extent of this movement was always low in comparison to that detected within a site or habitat (total recaptures $=1568$ ). However, thirteen of the displacements were recorded in three widely dispersed and low density populations in the Grampian Mountains (tot. rec. $=83$; see Table 6 of Brakefield 1982b). The length of these thirteen movements ranged from 150 to $320 \mathrm{~m}$. The latter example occurred over $24 \mathrm{~h}$ and was the longest detected at any study site.

The length of a displacement will depend on the distribution of suitable habitats. When traversing unsuitable habitat $M$. jurtina usually show a comparatively rapid, low and rectilinear flight (see Baker 1969). Examination of the study sites suggested that between-habitat movement is most likely to occur along topographical features such as hedges and grass/scrub or grass/woodland edges. On encountering the edge of a suitable habitat most $M$. jurtina exhibit a characteristic edge-type reaction involving a turn through $180^{\circ}$ or two turns of about $90^{\circ}$ (Baker 1978). Butterflies at Hightown frequently behaved similarly at the edge of habitat subunits. Areas of woodland are likely to form effective barriers to emigration although at the River Lyon locality in the Grampian Mountains butterflies were observed flying over lines of high trees.

Collecting outside the search areas at Hightown and Hall Road showed that emigration occurred from these populations but that its level was probably low (also see Brakefield 1979). For example, on the last day of the experiment at Hightown in 1976 a sample ( $n=$ 153) of females taken over $5 \mathrm{~h}$ from the only extensive grassland continuously connected to the study site contained five marked butterflies (about 200 were alive on this date). No $M$. jurtina could be found in this area (of $2.5 \mathrm{ha}$ ) of poor grassland in the following 2 years. In 1977 and 1978 the population at Hightown was studied from the beginning of emergence and the intensity of sampling was high (Table 1 of Brakefield 1982b). Because of this any butterfly whose wing condition at first capture indicated an age of older than 2 or 3 days was likely to be an immigrant. The proportions of these individuals were for males, two of 101 in 1977 and three of sixty-eight in 1978, and for females, none of seventy-one captured in both years. These figures show that the proportion of immigrants was unlikely to be more than $5 \%$ in these years. This is to be expected because of the relatively low density of M. jurtina in the less suitable habitat surrounding the study site.

\section{DISCUSSION}

The behaviour and microdistribution of butterflies at Hightown suggests that they exhibit some selection in response to the patchiness of the environment in relation to their principal resource requirements. An aggregated microdistribution has been found in some other species of butterflies with a more or less colonial population structure inhabiting temperate regions (Brussard, Ehrlich \& Singer 1974; Douwes 1975; Brown \& Ehrlich 1980). Male and female $M$. jurtina show different microdistributions at Hightown. The primary objective of males is to locate and mate with receptive females, with flower nectar being an 
additional resource requirement. Nectar is probably a more important resource for females. Stern \& Smith (1960) and Watt, Hoch \& Mills (1974) have demonstrated that nectar nutrients contribute to egg production in Colias butterflies. Female $M$. jurtina also require areas of suitable flora and vegetation structure for oviposition. Such areas will overlap with those where males have a comparatively high probability of mating. The coincidence between these areas may not be very close because of several factors including temporal change in habitat, the later emergence of females, the movement of freshly emerged females and variation in the ability of males to locate females in relation to vegetation structure. The observations on larval distribution and adult behaviour at Hightown suggest that the foraging area for nectar is larger than that utilized for mate location by males and for oviposition by females. The availability of sites for resting, dorsal basking and roosting is likely to be comparatively uniform within the habitat occupied by a population.

My observations of adult behaviour are similar to those of Baker (1978) who tracked a male and a female. However, Baker found that eggs were laid very near to soil level preferably amongst short grass that had been grazed or cut. Baker's observations were probably influenced by his study site having recently been grazed by cows. I have found that areas of predominantly short turf used for pasture promote emigration and are not usually preferred sites for oviposition. This is supported by the fact that both butterflies tracked by Baker immigrated into the meadow and then subsequently emigrated within 24 h. The rectilinear flights of at least $8 \mathrm{~m}$ between bouts of egg laying in short grass observed by Baker may not be the optimum strategy in areas where the habitat is highly suited to the species.

The present study confirms the low rate of interpopulation movement reported by some authors (references in Table 6 of Brakefield 1982b). This observation is contrary to Baker's (1978) view of $M$. jurtina as a mobile species. The frequency distribution for the distance travelled by butterflies at Hightown is leptokurtic. The majority of movements are short but more butterflies than expected move long distances. The relationship between the latter insects and the low proportion of emigrants is unclear. Many butterflies at Hightown did not move throughout the search area in their lifetime. A similar restriction of activity to areas of familiar habitat has been described in populations of Euphydryas editha (Brussard, Ehrlich \& Singer 1974) and Heodes virgaureae (Douwes 1975). The pattern of flight distances within a population of $M$. jurtina is dependent on the distribution of adult resources.

There is no obvious difference in average dispersal rate between the sexes of M.jurtina. However, males fly more often than females. This suggests that whilst in flight males show a stronger tendency to remain within a familiar area. Much of the time males spend flying is invested in searching for mates. Females fly to lay their eggs or to feed. Males can be considered to be more active in general than females.

The present study has confirmed Handford's (1973) suggestion that male and female $M$. jurtina occupy different ecological niches. The details of this difference and of associated differences in adult behaviour are examined in relation to the sexual dimorphism in wing spot pattern by Brakefield (1982a). Evidence is also presented that individual differences in dispersal behaviour are related to the spot variation within each sex.

\section{REFERENCES}

Baker, R. R. (1969). The evolution of the migratory habit in butterflies (Lepidoptera). Journal of Animal Ecology, 38, 703-746. 
Baker, R. R. (1978). The Evolutionary Ecology of Animal Migration. Hodder and Stoughton, London.

Brakefield, P. M. (1979). An experimental study of the maintenance of variation in spot pattern in Maniola jurtina. Unpublished $\mathrm{Ph}$. D. Thesis, University of Liverpool.

Brakefield, P. M. (1982a). The ecological genetics of quantitative characters in Maniola jurtina and other butterflies. Symposia of the Royal Entomological Society, 11. The Biology of Butterflies, (in press).

Brakefield, P. M. (1982b). Ecological studies on the butterfly Maniola jurtina in Britain. II. Population dynamics: the present position. Journal of Animal Ecology, 51, 727-738.

Brown, I. L. \& Ehrlich, P. R. (1980). Population biology of the checkerspot butterfly, Euphydryas chalcedona. Structure of the Jasper Ridge colony. Oecologia (Berlin), 47, 239-251.

Brussard, P. F., Ehrlich, P. R. \& Singer, M. C. (1974). Adult movements and population structure in Euphydryas editha. Evolution, 28, 408-415.

Clench, H. K. (1966). Behavioural thermoregulation in butterflies. Ecology, 48, 1021-1034.

Douwes, P. (1975). Distribution of a population of the butterfly Heodes virgaureae. Oikos, 26, 332-340.

Dowdeswell, W. H. \& Ford, E. B. (1955). Ecological genetics of Maniola jurtina in the Isles of Scilly. Heredity, 9, 265-272.

Dowdeswell, W. H., Ford, E. B. \& McWhirter, K. G. (1957). Further studies on isolation in the butterfly Maniola jurtina L. Heredity, 11, 51-65.

Dowdeswell, W. H., Ford, E. B. \& McWhirter, K. G. (1960). Further studies on the evolution of Maniola jurtina in the Isles of Scilly. Heredity, 14, 333-364.

Ford, E. B. (1975). Ecological Genetics (fourth edn). Chapman and Hall, London.

Handford, P. T. (1973). Patterns of variation in a number of genetic systems in Maniola jurtina: the boundary region. Proceedings of the Royal Society of London, Series B, 183, 265-284.

Mazurkiewicz, M. (1969). Elliptical modification of the home range pattern. Bulletin de l'Académie Polonaise des Sciences, Classe 2, 17, 427-431.

MeWhirter, K. G. (1957). A further analysis of variability in Maniola jurtina L. Heredity, 11, 359-371.

Randolph, S. E. (1977). Changing spatial relationships in a population of Apodemus sylvaticus with the onset of breeding. Journal of Animal Ecology, 46, 653-676.

Scali, V. \& Masetti, M. (1975). Variazioni intrastagionali dello spotting e selezione in Maniola jurtina L. (Lepidoptera, Satyridae). Academia Nazionale dei Lincei, Serie 8, 58, 244-256.

Scott, J. A. (1974). Mate-locating behaviour of butterflies. The American Midland Naturalist, 91, $103-117$.

Sokal, R. R. \& Rohif, F. J. (1981). Biometry (second edn). W. H. Freeman \& Co., San Francisco.

Southwood, T. R. E. (1966). Ecological Methods. Methuen, London.

Stern, V. M. \& Smith, R. F. (1960). Factors affecting egg production and oviposition in populations of Colias eurytheme Boisduval (Lepid., Pieridae). Hilgardia, 29, 411-454.

Tinbergen, N., Meeuse, B., Boerema, L. \& Variosseau, W. (1942). Die Balz des Samtfalters, Eumenis (Satyrus) semele. Zeitschrift für Tierpsychologie, 5, 182-226.

Watt, W. B., Chew, F. S., Synder, L. R. G., Watt, A. G. \& Rothschild, D. E. (1977). Population structure of Pierid butterflies. I. Numbers and movements of some montane Colias species. Oecologia (Berlin), 27, 1-22.

Watt, W. B., Hoch, P. C. \& Mills, S. G. (1974). Nectar resource use by Colias butterflies: chemical and visual aspects. Oecologia (Berlin), 14, 353-374.

(Received 8 July 1981) 